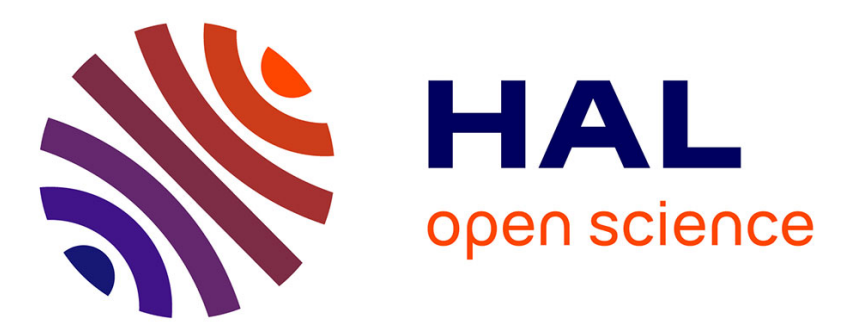

\title{
Global Architecture of Human Poly(A)-specific Ribonuclease by Atomic Force Microscopy in Liquid and Dynamic Light Scattering
}

Anna Niedzwiecka, Malgorzata Lekka, Per Nilsson, Anders Virtanen

\section{- To cite this version:}

Anna Niedzwiecka, Malgorzata Lekka, Per Nilsson, Anders Virtanen. Global Architecture of Human Poly(A)-specific Ribonuclease by Atomic Force Microscopy in Liquid and Dynamic Light Scattering. Biophysical Chemistry, 2011, 158 (2-3), pp.141. 10.1016/j.bpc.2011.06.010 . hal-00778542

\section{HAL Id: hal-00778542 \\ https://hal.science/hal-00778542}

Submitted on 21 Jan 2013

HAL is a multi-disciplinary open access archive for the deposit and dissemination of scientific research documents, whether they are published or not. The documents may come from teaching and research institutions in France or abroad, or from public or private research centers.
L'archive ouverte pluridisciplinaire HAL, est destinée au dépôt et à la diffusion de documents scientifiques de niveau recherche, publiés ou non, émanant des établissements d'enseignement et de recherche français ou étrangers, des laboratoires publics ou privés. 


\section{Accepted Manuscript}

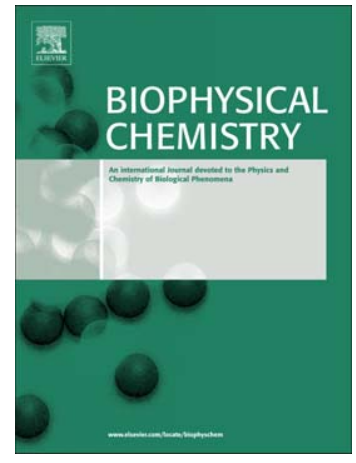

Global Architecture of Human Poly(A)-specific Ribonuclease by Atomic Force Microscopy in Liquid and Dynamic Light Scattering

Anna Niedzwiecka, Malgorzata Lekka, Per Nilsson, Anders Virtanen

PII: $\quad$ S0301-4622(11)00207-9

DOI: $\quad$ doi: $10.1016 /$ j.bpc.2011.06.010

Reference: $\quad$ BIOCHE 5541

To appear in: Biophysical Chemistry

Received date: 11 May 2011

Revised date: $\quad 16$ June 2011

Accepted date: 16 June 2011

Please cite this article as: Anna Niedzwiecka, Malgorzata Lekka, Per Nilsson, Anders Virtanen, Global Architecture of Human Poly(A)-specific Ribonuclease by Atomic Force Microscopy in Liquid and Dynamic Light Scattering, Biophysical Chemistry (2011), doi: 10.1016/j.bpc.2011.06.010

This is a PDF file of an unedited manuscript that has been accepted for publication. As a service to our customers we are providing this early version of the manuscript. The manuscript will undergo copyediting, typesetting, and review of the resulting proof before it is published in its final form. Please note that during the production process errors may be discovered which could affect the content, and all legal disclaimers that apply to the journal pertain. 


\section{Global Architecture of Human Poly(A)-specific Ribonuclease by Atomic Force Microscopy in Liquid and Dynamic Light Scattering}

Anna Niedzwiecka ${ }^{\mathrm{a},{ }^{*}}$, Malgorzata Lekka ${ }^{\mathrm{b}}$, Per Nilsson $^{\mathrm{c}, 1}$, Anders Virtanen ${ }^{\mathrm{c}}$

${ }^{a}$ Laboratory of Biological Physics, Institute of Physics, Polish Academy of Sciences, 32/46 Lotnikow Ave., 02-668 Warsaw, Poland;

${ }^{b}$ Laboratory of Biophysical Microstudies, Institute of Nuclear Physics, Polish Academy of Sciences, 31-342 Krakow, Poland;

${ }^{c}$ Department of Cell and Molecular Biology, Uppsala University, SE-751 24 Uppsala, Sweden.

${ }^{1}$ Present address: Laboratory for Proteolytic Neuroscience, RIKEN Brain Science Institute, 2-1 Hirosawa, Wako-shi, Saitama 351-0198, Japan, and Karolinska Institute, Dept. of Neurobiology, Care Sciences and Society, KI-Alzheimer Disease Research Center, Novum, Floor 5, SE-141 57 Huddinge, Sweden.

* corresponding author; e-mail: annan@ifpan.edu.pl; tel.: +48 228436601 ext. 3516; fax: $+48228430926$ 


\begin{abstract}
Deadenylation is the initial and often rate-limiting step in the main pathways of eukaryotic mRNA decay. Poly(A)-specific ribonuclease (PARN) is a eukaryotic enzyme that efficiently degrades mRNA poly(A) tails. Structural and functional studies have shown that human PARN is composed of at least three functional domains, i.e. the catalytic nuclease domain and two RNA binding domains, the R3H and the RNA recognition motif (RRM), respectively. However, the complete structure of the full length protein is still unknown. We have investigated the global architecture of human PARN by atomic force microscopy (AFM) imaging in buffered milieu and report for the first time the dimensions of the full length protein at subnanometre resolution. The AFM images of single PARN molecules reveal compact ellipsoidal dimers $(10.9 \times 7.6 \times 4.6 \mathrm{~nm})$. The dimeric form of PARN was confirmed by dynamic light scattering (DLS) measurements that rendered a molecular weight of 161 $\mathrm{kDa}$, in accordance with previous crystal structures of PARN fragments showing a dimeric composition. We discuss a putative internal arrangement of three functional domains within the full length PARN dimer.
\end{abstract}

\title{
Keywords
}

Atomic force microscopy (AFM); Dynamic light scattering (DLS); mRNA decay; Deadenylation; Poly(A)-specific ribonuclease (PARN); RNA recognition motif (RRM) 


\section{Introduction}

AFM has been successfully exploited for visualization of large, multicomponent biomolecular complexes, e.g. mRNA in complex with poly(A)-binding proteins (PABP) [1], and to show the existence of circular mRNA with its $3^{\prime}$ and 5 ' termini associated with each other through binding of eukaryotic translation initiation factors [2], as well as to follow protein movements [3]. Unfortunately, the resolution of AFM was usually limited, thus precluding the analysis of morphology of single proteins, particularly at buffered conditions. The best, subnanometre resolution has been obtained for two-dimensional protein crystals thanks to their periodic structure and electronic filtering of the images [4] and for large linear nucleic acids chains. Ultra high-resolution imaging of single proteins has also been possible for extensively desiccated protein samples [5] or in high vacuum [6] but those conditions are far away from a relevant physiological milieu.

On the other hand, the importance of water distribution [7] and hydration in structural studies of biological macromolecules was directly shown by comparison of the AFM images of DNA obtained in air and in aqueous solutions [8]. The heights of DNA double helices and superhelices measured in air were more than twice lower than in water. Thus, a challenge to visualization of biomolecules by AFM is to obtain a single protein image under buffered conditions with a reasonable resolution.

Deadenylation of eukaryotic mRNA is the initial and often rate-limiting step in the main pathways of mRNA decay [9] and therefore a key mechanism by which the half-lives of various mRNA classes is controlled. Poly(A)-specific ribonuclease (PARN) [10,11] is a mammalian deadenylase that participates in degradation of mRNA poly(A) tails [12]. PARN has been implicated to participate in nonsense-mediated mRNA decay [13], and is involved in regulation of cytoplasmic polyadenylation [14]. The activity of PARN is crucial during 
oocyte maturation [11,15,16], embryogenesis [17], early development [18], and in stress response [19], including DNA damage response [20,21]. PARN hydrolyses the mRNA poly(A) tail processively from the 3' end [22] and among the 3'-exoribonucleases, PARN is the only deadenylase known to concurrently bind to the $\mathrm{m}^{7} \mathrm{G}\left(5^{\prime}\right) \mathrm{ppp}\left(5^{\prime}\right) \mathrm{N}$ cap structure at the mRNA 5' end and the 3' end located poly(A) tail while hydrolyzing the poly(A) tail (Fig. 1a) [22-25]. The interaction with the cap structure enhances efficiency of deadenylation [22-24] and amplifies the processivity of the enzymatic action [25]. PARN belongs to the RNase D family of nucleases [26] which is a part of the superfamily of DEDD nucleases [27] that are characterized by the presence of four conserved acidic amino acids (Asp, Glu, Asp, Asp) in the catalytic centre and require divalent metal ions for efficient catalysis [28,29]. Our recent work revealed that the active site of PARN per se harbors specificity for recognition of adenosine residues and that the nucleotide context around the scissile bond determines the efficiency of the hydrolysis [30]. In addition to the active site, the RNA recognition motif (RRM) of PARN contributes to the poly(A) specificity of the enzyme [31].

The PARN sequence $[15,23]$ is composed of at least three functional domains: the catalytic nuclease domain [26], the R3H domain [32] and the RNA binding domain (RBD; or RNA recognition motif, RRM [33]). In addition to these domains, PARN also possesses an intriguing, $c a$. 130 amino acid long, mainly unstructured C-terminal tail that most likely acts as a recognition motif for both positive and negative regulators of PARN activity [20,34]. The quaternary structure of PARN was initially proposed to be oligomeric [22], and ultracentrifugation experiments has revealed a dimeric form in solution [35]. Likewise, a crystal structure of a fragment consisting of the N-terminal part of PARN (residues 1-430) without the RRM domain has shown that a tight dimer is held together by an aromatic-rich interface and a disulfide bridge between the nuclease domains of two PARN subunits [35] (Fig. 1b and c, PDB code: 2A1S, 2A1R). In apo-PARN(1-430), both the nuclease and the 
$\mathrm{R} 3 \mathrm{H}$ domain were visible and their spatial arrangement resembled a sea-horse shape with an empty space in the centre (Fig. 1c). The R3H domain was linked with the nuclease domain by a long helix and moved aside from it. On the other hand, the structure of PARN(1-430) in complex with an adenosine oligonucleotide revealed only the nuclease domain bound to the adenosine trinucleotide, while the R3H domain was disordered (Fig. 1b) [35].

In our previous work, we discovered that the PARN RRM is a unique, multifunctional domain that is responsible for molecular recognition of the 5' cap structure with a micromolar affinity and that the binding takes place at a non-canonical site where Trp475 plays the crucial role [31]. These surprising results yielded from biophysical and biochemical methods were confirmed by the structures of the PARN RRM complexed with a cap analogue, resolved by multidimensional NMR methods [36] and crystallography [37,38] (Fig. 1d). Although all three structures revealed the same cap binding mode, the overall PARN RRM appearance differed significantly depending on the exact amino acid sequence of the protein used for the structural determinations, crystal packing or buffer conditions. This raised the question of how the protein neighborhood of the RRM can influence the complete PARN structure.

In spite of several structure determinations of various parts of PARN, no complete structure of the full length human protein is yet available. Hence, there is a need to investigate the apparent architecture of PARN by alternative biophysical approaches, i.e. surface-based methods complemented by in-solution studies. Here we have used atomic force microscopy (AFM [39]) in liquid for imaging of immobilized proteins, as well as dynamic light scattering (DLS) measurements and gel filtration experiments in solution to find estimates of the protein shape. We report for the first time the dimensions of the complete PARN molecule, which previously has not been possible to obtain neither by crystallographic studies using truncated versions of PARN [35,38] (Fig. 1) nor from solution studies [40]. 


\section{Materials and methods}

Expression and purification of PARN and PARN(443-560). His-Tagged full length human PARN (residues 1-639, MW $76.2 \mathrm{kDa} / \mathrm{monomer}$, including His-tag) and its fragment containing the RRM with a 50 amino acids long C-terminal tail (residues 443-560, MW 17.2 $\mathrm{kDa}$ /monomer, including His-tag) were expressed from E. coli strain BL21(DE3) [41]. The soluble protein was purified as described previously [41] and dialyzed into buffer: HEPES/KOH $20 \mathrm{mM}$ pH 7, glycerol 10\%, $\mathrm{MgCl}_{2} 1.5 \mathrm{mM}$, EDTA $0.2 \mathrm{mM}$, DTT $0.5 \mathrm{mM}, 100$ $\mathrm{mM} \mathrm{KCl}$. The proteins purity (90-95\%) was analyzed by SDS-PAGE followed by Coomassie staining. Protein samples were centrifuged for $5 \mathrm{~min}$ at $13000 \mathrm{rpm}$ at $4{ }^{\circ} \mathrm{C}$ and softly degassed prior to AFM measurements. Samples used for DLS were filtered through $0.1 \mu \mathrm{m}$ (PARN) or $100 \mathrm{kDa}(\mathrm{RRM})$ pores immediately before measurements.

Atomic force microscopy imaging. Freshly cleaved mica was covered by (3aminopropyl)triethoxysilane (440140, Sigma) under vacuum overnight, then immersed in filtered $1 \%$ glutaraldehyde solution (49632-1EA, Fluka) for 30-60 min., and rinsed with buffer. The glutaraldehyde-covered mica surface was always kept in liquid to avoid drying and cracking. PARN was diluted to a final concentration of $7-140 \mathrm{nM}$ per monomer. The samples of $30 \mu \mathrm{L}$ were deposited onto the substrate for $5-10$ min at $4{ }^{\circ} \mathrm{C}$. Then the surface was rinsed with buffer, and a $50 \mu \mathrm{L}$ droplet was left for measurements.

AFM imaging was performed using a home-built device [42] equipped with a liquid cell [43] and working in a contact mode and using Agilent N9410S - Series 5500 AFM/SPM System. Samples were scanned in buffer at ambient temperature, at line frequencies of 2.5-3.5 Hz. Two types of AFM probes were used: standard oxygen sharpened silicon nitride probes with the nominal radius of curvature of $20 \mathrm{~nm}$, at $315 \mu \mathrm{m}$ length cantilevers with the spring 
constant of $0.01 \mathrm{~N} / \mathrm{m}$ (MSCT-AUHW, Veeco), and high precision high-density carbon (HDC) tips with 2-3 nm radius of curvature (Super Sharp Short, Nanotools), individually tested by electron microscopy by the manufacturer. The tips were placed on soft cantilevers with the spring constant of $0.002-0.016 \mathrm{~N} / \mathrm{m}$ and the length of $90-110 \mu \mathrm{m}$ (OMCL-BLRC150VB-C1, Olympus). Contact-mode imaging was performed with the weakest possible stress force provided by application of the cantilevers with the lowest available spring constants and determination of the set-point by multiple sampling of the approach curve, to avoid altering of the measured dimensions of soft protein molecules.

Calibration in $\mathrm{X}, \mathrm{Y}$ and $\mathrm{Z}$ directions was performed using TGQ1 and TGZ1 gratings (NT-MDT). Images were processed by plane subtraction, horizontal line normalization and median based smoothing using the software of Lekki et al.[42] The "zoom option" was performed by doubling of the resolution in $\mathrm{X}$ and $\mathrm{Y}$ directions, and by replacing every original point with four pixels, preserving dimensions of the studied structures.

The apparent diameters of molecules (Fig. 2,3) were read as the full width at half maximum $(F W H M)$ from the scans recorded in the range of $\sim 300 \times 300 \mathrm{~nm}$ to $\sim 600 \times 600$ $\mathrm{nm}$. Images of small molecules are apparently magnified since radii of curvature of the AFM tips $(R)$ are comparable with dimensions of the visualized objects. The actual lengths of the long $(a)$ and the short $(b)$ axis of the individual molecular ellipsoids were calculated from the relationship between the actual dimension (Dim, where Dim is $a$ or $b$ ) and the corresponding value of $F W H M$ measured by a tip of the radius of curvature of $R$, according to Engel et al. [44], using the equation:

$$
\operatorname{Dim}=\sqrt{4 \cdot R^{2}+F W H M^{2}}-2 \cdot R
$$

Afterwards, Gaussian distributions were calculated for $a, b$, and also for the height of the molecule, $h$, to determine the mean values and the standard errors of the mean (S.E.M.), and frequency histograms were generated (Table 1, Fig. 4). 
Dynamic light scattering. DLS measurements were performed on Zetasizer Nano ZS (Malvern) using Non-Invasive Back Scatter (NIBS) detection at $173^{\circ}$, equipped with the HeNe $4.0 \mathrm{~mW}$ red laser $(633 \mathrm{~nm})$ and with automatically determined position of moveable lens. The detectable size range of hydrodynamic diameters was $0.6 \mathrm{~nm}$ to $6 \mu \mathrm{m}$, at the concentration range of $0.1 \mathrm{mg} / \mathrm{ml}$ Lys to $40 \mathrm{wt} / \mathrm{vol} \%$. Four repeats of experiments were performed at $20.0{ }^{\circ} \mathrm{C}$ in a thermostated quartz cell (ZEN2112) for samples (20-60 $\mu$ l) of PARN at $0.33 \mathrm{mg} / \mathrm{ml}$ and PARN(443-560) at $0.4 \mathrm{mg} / \mathrm{ml}$. The signal scattered by the samples was measured repeatedly in runs of 10 to $90 \mathrm{~s}$. The system was calibrated using Nanosphere Size standard - NIST Traceable Mean Diameter (Duke Scientific) taking into account the influence of all buffer components on the viscosity and the refractive index of the dispersant.

The hydrodynamic diameter, $D_{h}$, is the size of a hypothetical hard sphere that diffuses in the same fashion as that of the particle being measured, and is indicative of the apparent size of the hydrated particle. Size distributions by scattering intensity and volume (mass), and molecular weight $(M W)$ estimates were calculated from DLS, as follows.

Light is scattered in a quasi-elastic manner by interactions with electrons of molecules in a solution with the incident radiation. The oscillating electric field causes a vibration of electrons turning them into oscillating dipoles that reemit radiation. The emission power spectrum is broadened in the frequency domain due to the Doppler effect on the Brownian motion of scattering macromolecules and hence due to their diffusion coefficient $(D)$. The diffusion coefficient is approximately related to the hydrodynamic radius $\left(R_{h}\right)$.

Fluctuations in the intensity of light scattered by a small volume are described by an autocorrelation function $\left(g_{1}(t)\right)$. For small monodisperse spherical particles, the normalized autocorrelation function of scattered electric field is [45]:

$$
g_{1}(t)=e^{-D \bar{Q}_{t}^{2}}
$$


where $\vec{Q}$ is the scattering vector resulting from the difference of the scattered and the incident wave vectors, and $\mathrm{t}$ is the time interval for displacement of the scattering particle. $D$ is related to the reciprocal of the characteristic decay time $(\Gamma)$ :

$$
\Gamma=D \vec{Q}^{2}
$$

For polydisperse systems with different $\Gamma$ values:

$$
g_{1}(t)=\sum_{i} a_{i} e^{-\Gamma t}
$$

where $a_{i}$ are amplitudes, proportional to molecular weight and concentration of species. In terms of cumulant analysis [46], the above equation can be developed into:

$$
\ln g_{1}(t)=-\overline{\Gamma t}+\mu_{2} t^{2}+\ldots
$$

where $\bar{\Gamma}$ is the first cumulant related to the average decay rate and $\mu_{2}$ is the second cumulant (normalized variance of the distribution).

An inverse Laplace transform yields the distribution of decay rates from which the $D$ values can be determined, and then $R_{h}$ (and hydrodynamic diameters, $D_{h}$ ) calculated using the Stokes-Einstein equation:

$$
D=\frac{k_{B} T}{6 \pi \eta R_{h}}
$$

where $k_{B}$ is the Boltzmann constant, $T$ is temperature, $\eta$ is viscosity.

Molecular weight calculations were performed by DTS v5.0 software, using a logarithmic $M W\left(R_{h}\right)$ standard curve for globular proteins based on experimental data for several well-characterized proteins in the range of 10 to $1000 \mathrm{kDa}$, provided by the manufacturer.

Gel filtration. Recombinant PARN(443-560), expressed and purified as described above, was dialyzed into $50 \mathrm{mM} \mathrm{KH} \mathrm{KO}_{4} / \mathrm{K}_{2} \mathrm{HPO}_{4}$ and $200 \mathrm{mM} \mathrm{NaCl}$ at $\mathrm{pH}$ 7.0. $20 \mu \mathrm{L}$ of 80 
$\mu \mathrm{M}$ PARN(443-560) was centrifuged for $30 \mathrm{~min}$ at $13000 \mathrm{rpm}$ at $4{ }^{\circ} \mathrm{C}$. The sample was injected, using a $20 \mu 1$ loop, into a SMART fractionation system (Pharmacia/GE Healthcare) and subsequently fractionated by Superdex ${ }^{\mathrm{TM}} 200$ PC3.2/30 column (GE Healthcare) chromatography at a flow rate of $40 \mu \mathrm{l} / \mathrm{min}$ at $4{ }^{\circ} \mathrm{C}$.

Intrinsic disorder and secondary structure predictions. Disorder probability predictions were performed by the open access DISOPRED server [47] and secondary structure predictions were run at the PSIPRED server [48,49].

\section{Results and Discussion}

Ellipsoidal shape and dimensions of full length PARN dimer. In order to characterize morphology of a human PARN molecule containing all three functional domains, we used the full length recombinant protein that was previously shown to harbor the main properties of native PARN obtained from mammalian tissues, $i$. $e$. hydrolytic activity, specificity for poly(A) and ability to bind the 5' cap structure [34].[41] PARN molecules were deposited from nanomolar solutions on the chemically modified mica surface, and the molecules covalently bound to the substrate were monitored by contact-mode AFM. Two types of AFM tips were used to exclude possible artifacts related to the tips geometry. Typical AFM images of PARN in buffered conditions, obtained using tips with the radius of curvature of $20 \mathrm{~nm}$ and 2-3 nm, are shown in Fig. 2 and Fig. 3, respectively.

The images revealed PARN molecules with a compact globular shape that can be approximated by an ellipsoid. The height as well as the long and the short axes of several tens of randomly oriented molecules were subsequently measured and actual dimensions of PARN, corrected for broadening of the apparent image due to finite sizes of the tips, were 
calculated from Gaussian distributions. Frequency histograms in Fig. 4 and Table 1 summarize the results determined with the use of the sharp and broad tips. The results show that a single PARN molecule has dimensions of $10.9 \times 7.6 \times 4.6 \mathrm{~nm}$, and a volume of about $200 \mathrm{~nm}^{3}$. The approximate volume expected for a globular protein of the molecular weight corresponding to the PARN monomer is $97 \mathrm{~nm}^{3}$ [50]. Hence, the AFM images imply a dimeric form of full length human PARN.

The results collected by the two types of tips agreed to each other within 95\% CI. Imaging with the sharp tips gave slightly less scattered results with better Gaussian distribution described by lower Kolmogorov-Smirnov coefficients [51]. A relatively larger discrepancy in the height measurements could partially originate from possible variations in molecule deformation induced by variable values of the loading forces applied to the surface, which could lead to the apparently decreased height measured by the broad tips. Additionally, variations could be due to possible penetration of the substrate by the $2-3 \mathrm{~nm}$ tips, since the chemically modified mica surface appeared more porous on this scale. The substrate roughness (root-mean-square, R.M.S.) was a dominating source of errors. The R.M.S. value obtained from control scanning with the sharp tips was $0.61 \mathrm{~nm}$ while the broad tips yielded only $0.34 \mathrm{~nm}$. This could lead to the slightly overestimated height values in case of the sharp tips. Since the two types of tips could potentially cause opposing artifacts, averaging of the results should provide a good estimate of the actual height.

To further investigate the size of full length PARN in solution, dynamic light scattering measurements were performed using micromolar concentrations of the protein (Fig. 5a). The DLS results yielded a hydrodynamic diameter of the PARN molecule of about 10.4 $\mathrm{nm}$ and a molecular weight of about $160 \mathrm{kDa}$ (Table 2), which corresponded to the dimeric form of the protein observed by AFM. In general, the hydrodynamic diameter is in accordance with the length of the long axis established by AFM. However, these two 
quantities should not be compared directly, since $D_{h}$ is an abstract parameter that describes a hypothetical hard sphere corresponding to diffusion of the hydrated protein molecule, while the dimensions measured by AFM are geometric estimates of the molecular size. Nevertheless, the DLS data supported a dimeric form of PARN in solution.

Dimerization of PARN(443-560). Surprisingly, the DLS measurements of PARN(443560), a $17 \mathrm{kDa}$ fragment encompassing the RRM and a 50-amino acid long C-terminal sequence, resulted in a hydrodynamic diameter of about $5.5 \mathrm{~nm}$ and a molecular weight of about $37 \mathrm{kDa}$ (Fig. 5b, Table 2). Since the PARN(443-560) samples were monodisperse, these results enable us to draw a reliable conclusion that the PARN(443-560) fragment could exist predominantly as a dimer by itself.

To confirm the dimerisation properties of the PARN(443-560) fragment in an independent assay, we subjected PARN(443-560) to size exclusion chromatography (gel filtration) using Superdex 200 as the matrix. In the resulting chromatogram, shown in Fig. 5c, a significant peak corresponding to a molecular size of a PARN(443-560) dimer could be identified in addition to a dominant peak that in molecular size corresponds to monomeric PARN(443-560). One difference was observed that could be potentially related to buffer conditions and/or the method of analysis, i.e. that the dimer fraction detected by gel filtration was smaller than by DLS. However, this data provides further support for the possibility of dimerisation of a PARN fragment encompassing a C-terminally extended RRM.

It has previously been reported that a shorter PARN fragment, i.e. PARN(445-540), eluted mainly as a monomer with a 5\% dimeric fraction in gel filtration experiments [37]. This suggests that the C-terminally RRM fragment of PARN, i.e. PARN(443-560), is prone to dimerise due to the presence of residues 541-560. The quite different dimerisation properties of the PARN RRM domains with shorter or longer C-terminal tail extensions are in agreement 
with the fact that all known PARN RRM structures resolved by NMR or crystallography [3638] are also divergent, strongly influenced by the exact amino acid sequence of the protein fragment, buffer composition and the crystallographic contacts. The observed PARN RRM structures are thus highly sensitive to the overall protein context.

To identify the molecular origins of the PARN(443-560) dimerisation we investigated, by bioinformatics methods using DISOPRED and PSIPRED servers, [47] the intrinsic ability of each amino acid residue to form an ordered protein structure (Fig. 6a).[48,49] Similar bioinformatics analysis was done previously by the PONDR software,[52] but no residues belonging to a well-ordered fragment within the C-terminal tail was identified.

Disorder probability and secondary structure predictions show unambiguously that there is a potentially well ordered ${ }^{551} \mathrm{HYYR}^{554}$ motif within the long, mainly unstructured Cterminal tail of human PARN (Fig. 6c). The HYYR motif is located in the centre of a sequence (residues 549-556), which has a near palindromic character flanked by QN and NN (Fig. 6d), and could potentially self-associate exploiting cation- $\pi$ interactions and contacts similar to several known tyrosine/glutamine/asparagine zippers [53-56]. In general, the Cterminus of PARN is divergent among species, but residues that define the putative selfassociating sequence, encompassing the flanking residues Q549 and N556 with aromatic or non-polar amino acids, e.g. Tyr, Phe and His, between them, are conserved. Hence a zipper motif, as proposed above for the human PARN, appears very likely in PARN originating from different sources in spite of the lack of strict sequence conservation. A second possible cause of PARN(443-560) dimerisation could be a disulfide bridge involving Cys543, although this is less likely, since all experiments have been conducted at reducing conditions.

Taking together the experimental results and the bioinformatics analysis, we propose that the C-terminal tail of the RRM might be one of the dimerisation factors for PARN. Due to this intrinsic tendency to dimerisation, it is probable that these C-terminal zipper motifs 
from two PARN subunits connect directly to each other within the full length protein, contributing to the dimerisation interface beside the nuclease domains.

Finally, we note that at present one cannot exclude a possibility that dimerisation between two RRM domains occurs between two unique dimers of full length PARN and thereby forming a potential tetrameric structure of PARN. Such potential tetramers are present in the crystallographic asymmetric unit [38] as well as the $25 \%$ level of the full length PARN polydispersity detected in DLS experiments and some scattering of the AFM geometrical data make this possibility open. If this is the case, it implies that PARN under certain cellular conditions might form larger oligomers than a dimer, e.g. a tetramer being a dimer of two PARN dimers.

Possible internal arrangement of PARN domains. The three PARN domains could potentially be located in a number of relative orientations. Reconstruction of the hypothetical full length PARN molecule based on two fragmentary crystal structures [38] was the first speculative approach to visualization of putative arrangement of the functional domains within the dimer. However, that reconstruction kept the empty space in the centre of the molecule, as it was in the apo-structure of the nuclease and the R3H domains of PARN [35].

While buffer milieu and crystal packing can alter conformation of multidomain proteins, the strongest factor that can influence the structures resolved by X-ray diffraction is the absence of large domains (>100-200 amino acids long in each monomer) in the sequence of the previously crystallized protein fragments. For that reason, crystal structures should be confronted with other methods, in-solution or surface-based, suitable for such a large protein containing 100 a.a. long fragments putatively without well defined secondary structure.

The compact ellipsoidal shape of full length PARN recorded by AFM (Fig. 2, 3) and the intrinsic dimerisation of the RRM C-terminal tail revealed by DLS (Table 2), and gel 
filtration (Fig. 5c) shed new light on the global architecture of PARN. The results obtained provide an experimental basis for structural anticipation regarding the internal arrangement of the domains within the full length molecule. In the crystal structure [35], the longest distance between the extreme residues belonging to two $\mathrm{R} 3 \mathrm{H}$ domains of the PARN(1-430) dimer is $13.5 \mathrm{~nm}$ (Fig. 1c). This length exceeds the maximal size of PARN revealed by AFM (10.9 $\mathrm{nm}$, Table 1). Therefore, the location of the $\mathrm{R} 3 \mathrm{H}$ domain as shown by crystallography for apo-PARN(1-430) [35] might not be realized in the full length protein. Moreover, the fact that the R3H domain was disordered both in the complex of PARN(1-430) with the adenosine oligonucleotide [35] (Fig. 1b) and in the complex of PARN(1-510) with the cap analogue[38] (Fig. 1d) might suggest that its placement in relation to the rest of the molecule was uncertain. Therefore, one alternative structural arrangement would be that the $\mathrm{R} 3 \mathrm{H}$ domain in full length PARN forms, together with the RRM domain, a continuous surface of the PARN dimer. The compact arrangement is consistent with both AFM images and DLS results as well as with the disordering of the whole $\mathrm{R} 3 \mathrm{H}$ domain that has been observed in different crystal structures [35].[38] This hypothesis is further supported by earlier findings that the R3H and RRM domains should be located in the close proximity, since $\mathrm{R} 3 \mathrm{H}$ exerts a stabilization effect preventing the protein from aggregation [40], as well as by the proposed interactions between the R3H and RRM domains [57].

\section{Conclusions}

Visualization of PARN by AFM in liquid has revealed for the first time a globular, compact, ellipsoidal shape of a full length PARN dimer in buffered milieu. Determination of the overall geometry of hydrated PARN molecules with subnanometre resolution provided 
information that is complementary to the known, incomplete crystal structures and yielded an important mesoscopic structural description of human poly(A)-specific ribonuclease.

\section{Acknowledgments}

We thank Dr. Janusz Lekki for helpful assistance with the microscope, Prof. Ryszard Stolarski for critical reading of the manuscript, Drs. Krzysztof Ginalski and Niklas Henriksson for fruitful discussions, and Nanotools GmbH (www.nano-tools.com) for partial financial support. This work was supported by grant N N301 267137 from Polish Ministry of Science and Higher Education, the Swedish Research Council, the Linneus Support from the Swedish Research Council to the Uppsala RNA Research Centre and the Lennanders Foundation at Uppsala University. 


\section{References}

[1] B. L. Smith, D. R. Gallie, H. Le, and P. K. Hansma, Visualization of poly(A)-binding protein complex formation with poly(A) RNA using atomic force microscopy, J. Struct. Biol. 119 (1997) 109-117.

[2] S. E. Wells, P. E. Hillner, R. D. Vale, and A. B. Sachs, Circularization of mRNA by eukaryotic translation initiation factors, Mol. Cell 2 (1998) 135-140.

[3] R. Bash, H. Wang, C. Anderson, J. Yodh, G. Hager, S. M. Lindsay, and D. Lohr, AFM imaging of protein movements: Histone $\mathrm{H} 2 \mathrm{~A}-\mathrm{H} 2 \mathrm{~B}$ release during nucleosome remodeling, FEBS Lett. 580 (2006) 4757-4761.

[4] D. J. Muller, K. T. Sapra, S. Scheuring, A. Kedrov, P. L. Frederix, D. Fotiadis, and A. Engel, Single-molecule studies of membrane proteins, Current Opinion in Structural Biology 16 (2006) 489-495.

[5] N. H. Thomson, The substructure of immunoglobulin $\mathrm{G}$ resolved to $25 \mathrm{kDa}$ using amplitude modulation AFM in air, Ultramicroscopy 105 (2005) 103-110.

[6] E. Davies, K. S. Teng, R. S. Conlan, and S. P. Wilks, Ultra-high resolution imaging of DNA and nucleosomes using non- contact atomic force microscopy, FEBS Lett. 579 (2005) 1702-1706.

[7] K. Kimura, S. Ido, N. Oyabu, K. Kobayashi, Y. Hirata, T. Imai, and H. Yamada, Visualizing water molecule distribution by atomic force microscopy, J. Chem. Phys. 132 (2010).

[8] K. Rippe, N. Mucke, and J. Langowski, Superhelix dimensions of a 1868 base pair plasmid determined by scanning force microscopy in air and in aqueous solution, Nucleic Acids Res. 25 (1997) 1736-1744. 
[9] P. Mitchell and D. Tollervey, mRNA stability in eukaryotes, Curr. Opin. Genet. Dev. 10 (2000) 193-198.

[10] J. Astrom, A. Astrom, and A. Virtanen, In vitro deadenylation of mammalian mRNA by a HeLa cell 3' exonuclease, EMBO J. 10 (1991) 3067-3071.

[11] C. G. Korner, M. Wormington, M. Muckenthaler, S. Schneider, E. Dehlin, and E. Wahle, The deadenylating nuclease (DAN) is involved in poly(A) tail removal during the meiotic maturation of Xenopus oocytes, EMBO J. 17 (1998) 5427-5437.

[12] R. Parker and H. W. Song, The enzymes and control of eukaryotic mRNA turnover, Nat. Struct. Mol. Biol. 11 (2004) 121-127.

[13] F. Lejeune, X. J. Li, and L. E. Maquat, Nonsense-mediated mRNA decay in mammalian cells involves decapping, deadenylating, and exonucleolytic activities, Mol. Cell 12 (2003) 675-687.

[14] J. H. Kim and J. D. Richter, Opposing polymerase-deadenylase activities regulate cytoplasmic polyadenylation, Mol. Cell 24 (2006) 173-183.

[15] P. R. Copeland and M. Wormington, The mechanism and regulation of deadenylation: Identification and characterization of Xenopus PARN, RNA 7 (2001) 875-886.

[16] B. M. Lingenfelter, R. A. Dailey, E. K. Inskeep, M. W. Vernon, D. H. Poole, J. D. Rhinehart, and J. B. Yao, Changes of maternal transcripts in oocytes from persistent follicles in cattle, Mol. Reprod. Dev. 74 (2007) 265-272.

[17] S. V. Reverdatto, J. A. Dutko, J. A. Chekanova, D. A. Hamilton, and D. A. Belostotsky, MRNA deadenylation by PARN is essential for embryogenesis in higher plants, RNA 10 (2004) 1200-1214.

[18] Y. Chiba, M. A. Johnson, P. Lidder, J. T. Vogel, H. van Erp, and P. J. Green, AtPARN is an essential poly(A) ribonuclease in Arabidopsis, Gene 328 (2004) 95-102. 
[19] N. Nishimura, N. Kitahata, M. Seki, Y. Narusaka, M. Narusaka, T. Kuromori, T. Asami, K. Shinozaki, and T. Hirayama, Analysis of ABA Hypersensitive Germination2 revealed the pivotal functions of PARN in stress response in Arabidopsis, Plant J. 44 (2005) 972-984.

[20] M. A. Cevher, X. K. Zhang, S. Fernandez, S. Kim, J. Baquero, P. Nilsson, S. Lee, A. Virtanen, and F. E. Kleiman, Nuclear deadenylation/polyadenylation factors regulate 3 ' processing in response to DNA damage, Embo Journal 29 (2010) 1674-1687.

[21] H. C. Reinhardt, P. Hasskamp, I. Schmedding, S. Morandell, M. A. T. M. van Vugt, X. Z. Wang, R. Linding, S. E. Ong, D. Weaver, S. A. Carr, and M. B. Yaffe, DNA Damage Activates a Spatially Distinct Late Cytoplasmic Cell-Cycle Checkpoint Network Controlled by MK2-Mediated RNA Stabilization, Molecular Cell 40 (2010) $34-49$.

[22] J. Martinez, Y. G. Ren, A. C. Thuresson, U. Hellmann, J. Astrom, and A. Virtanen, A 54-kDa fragment of the poly $(\mathrm{A})$-specific ribonuclease is an oligomeric, processive, and cap-interacting poly(A)-specific 3 ' exonuclease, J. Biol. Chem. 275 (2000) $24222-24230$.

[23] E. Dehlin, M. Wormington, C. G. Korner, and E. Wahle, Cap-dependent deadenylation of mRNA, EMBO J. 19 (2000) 1079-1086.

[24] M. Gao, D. T. Fritz, L. P. Ford, and J. Wilusz, Interaction between a poly(A)-specific ribonuclease and the 5 ' cap influences mRNA deadenylation rates in vitro, Mol. Cell 5 (2000) 479-488.

[25] J. Martinez, Y. G. Ren, P. Nilsson, M. Ehrenberg, and A. Virtanen, The mRNA cap structure stimulates rate of poly(A) removal and amplifies processivity of degradation, J. Biol. Chem. 276 (2001) 27923-27929. 
[26] M. J. Moser, W. R. Holley, A. Chatterjee, and I. S. Mian, The proofreading domain of Escherichia coli DNA polymerase I and other DNA and/or RNA exonuclease domains, Nucleic Acids Res. 25 (1997) 5110-5118.

[27] Y. Zuo and M. P. Deutscher, Exoribonuclease superfamilies: structural analysis and phylogenetic distribution, Nucleic Acids Res. 29 (2001) 1017-1026.

[28] Y. G. Ren, J. Martinez, and A. Virtanen, Identification of the active site of poly(A)specific ribonuclease by site-directed mutagenesis and Fe2+-mediated cleavage, J. Biol. Chem. 277 (2002) 5982-5987.

[29] Y. G. Ren, L. A. Kirsebom, and A. Virtanen, Coordination of divalent metal ions in the active site of poly(A)-specific ribonuclease, J. Biol. Chem. 279 (2004) 4870248706.

[30] N. Henriksson, P. Nilsson, M. S. Wu, H. W. Song, and A. Virtanen, Recognition of adenosine residues by the active site of poly(A)-specific ribonuclease, Journal of Biological Chemistry 285 (2010) 163-170.

[31] P. Nilsson, N. Henriksson, A. Niedzwiecka, N. A. A. Balatsos, K. Kokkoris, J. Eriksson, and A. Virtanen, A multifunctional RNA recognition motif in poly(A)specific ribonuclease with cap and poly(A) binding properties, Journal of Biological Chemistry 282 (2007) 32902-32911.

[32] N. V. Grishin, The R3H motif: A domain that binds single-stranded nucleic acids, Trends Biochem. Sci. 23 (1998) 329-330.

[33] C. Maris, C. Dominguez, and F. H. T. Allain, The RNA recognition motif, a plastic RNA-binding platform to regulate post-transcriptional gene expression, FEBS J. 272 (2005) 2118-2131. 
[34] N. A. A. Balatsos, P. Nilsson, C. Mazza, S. Cusack, and A. Virtanen, Inhibition of mRNA deadenylation by the nuclear cap binding complex (CBC), J. Biol. Chem. 281 (2006) 4517-4522.

[35] M. S. Wu, M. Reuter, H. Lilie, Y. Y. Liu, E. Wahle, and H. W. Song, Structural insight into poly(A) binding and catalytic mechanism of human PARN, EMBO J. 24 (2005) 4082-4093.

[36] T. Nagata, S. Suzuki, R. Endo, M. Shirouzu, T. Terada, M. Inoue, T. Kigawa, N. Kobayashi, P. Guntert, A. Tanaka, Y. Hayashizaki, Y. Muto, and S. Yokoyama, The RRM domain of poly(A)-specific ribonuclease has a noncanonical binding site for mRNA cap analog recognition, Nucleic Acids Res 36 (2008) 4754-4767.

[37] T. Monecke, S. Schell, A. Dickmanns, and R. Ficner, Crystal structure of the RRM domain of poly(A)-specific ribonuclease reveals a novel m(7)G-cap-binding mode, Journal of Molecular Biology 382 (2008) 827-834.

[38] M. S. Wu, P. Nilsson, N. Henriksson, A. Niedzwiecka, M. K. Lim, Z. Cheng, K. Kokkoris, A. Virtanen, and H. W. Song, Structural basis of m(7)GpppG binding to poly(A)-specific ribonuclease, Structure 17 (2009) 276-286.

[39] G. Binnig, C. F. Quate, and C. Gerber, Atomic force microscope, Phys. Rev. Lett. 56 (1986) 930-933.

[40] W. F. Liu, A. Zhang, G. J. He, and Y. B. Yan, The R3H domain stabilizes poly(A)specific ribonuclease by stabilizing the RRM domain, Biochem. Biophys. Res. Commun. 360 (2007) 846-851.

[41] P. Nilsson and A. Virtanen, Expression and purification of recombinant poly (A)specific ribonuclease (PARN), Int. J. Biol. Macromol. 39 (2006) 95-99.

[42] J. Lekki, U. Vo, M. Sowa (Lekka), B. Cleff, and Z. Stachura, Construction and first experiments using Scanning Force Microscope, Report IFJ no. 1690/AP (1995). 
[43] M. Lekka, J. Lekki, M. Marszalek, P. Golonka, Z. Stachura, B. Cleff, and A. Z. Hrynkiewicz, Local elastic properties of cells studied by SFM, Applied Surface Science 141 (1999) 345-349.

[44] A. Engel, C. A. Schoenenberger, and D. J. Muller, High resolution imaging of native biological sample surfaces using scanning probe microscopy, Current Opinion in Structural Biology 7 (1997) 279-284.

[45] H.Brunner and K.Dransfeld, in: Light scattering by macromolecules, eds. W.Hoppe, W.Lohmann, H.Markl, and H.Ziegler, Biophysics (Springer-Verlag, New York, 1983) pp. 93-100.

[46] D. E. Koppel, Analysis of Macromolecular Polydispersity in Intensity Correlation Spectroscopy: The Method of Cumulants, J. Chem. Phys. 57 (1972) 4814-4820.

[47] J. J. Ward, L. J. McGuffin, K. Bryson, B. F. Buxton, and D. T. Jones, The DISOPRED server for the prediction of protein disorder, Bioinformatics 20 (2004) 2138-2139.

[48] D. T. Jones, Protein secondary structure prediction based on position-specific scoring matrices, Journal of Molecular Biology 292 (1999) 195-202.

[49] K. Bryson, L. J. McGuffin, R. L. Marsden, J. J. Ward, J. S. Sodhi, and D. T. Jones, Protein structure prediction servers at University College London, Nucleic Acids Research 33 (2005) W36-W38.

[50] T.E.Creighton, Proteins: structures and molecular properties. (W. H. Freeman and Co., New York, 1993).

[51] M.H.DeGroot, Probability and Statistics (Addison Wesley, 1991).

[52] G. J. He, A. Zhang, W. F. Liu, Y. Cheng, and Y. B. Yan, Conformational stability and multistate unfolding of poly(A)-specific ribonuclease, Febs Journal 276 (2009) 28492860. 
[53] M. F. Perutz, T. Johnson, M. Suzuki, And J. T. Finch, Glutamine Repeats as Polar Zippers - Their Possible Role in Inherited Neurodegenerative Diseases, Proc. Natl. Acad. Sci. U. S. A. 91 (1994) 5355-5358.

[54] S. Duquerroy, A. N. Vigouroux, P. J. M. Rottier, F. A. Rey, and B. J. Bosch, Central ions and lateral asparagine/glutamine zippers stabilize the post-fusion hairpin conformation of the SARS coronavirus spike glycoprotein, Virology 335 (2005) 276285.

[55] R. Nelson, M. R. Sawaya, M. Balbirnie, A. O. Madsen, C. Riekel, R. Grothe, and D. Eisenberg, Structure of the cross-beta spine of amyloid-like fibrils, Nature 435 (2005) 773-778.

[56] M. R. Sawaya, S. Sambashivan, R. Nelson, M. I. Ivanova, S. A. Sievers, M. I. Apostol, M. J. Thompson, M. Balbirnie, J. J. W. Wiltzius, H. T. McFarlane, A. O. Madsen, C. Riekel, and D. Eisenberg, Atomic structures of amyloid cross-beta spines reveal varied steric zippers, Nature 447 (2007) 453-457.

[57] A. Zhang, W. F. Liu, and Y. B. Yan, Role of the RRM domain in the activity, structure and stability of poly(A)-specific ribonuclease, Arch. Biochem. Biophys. 461 (2007) 255-262.

[58] The PyMOL Molecular Graphics System, Version 0.99rc6. (0.99rc6). 2006. DeLano Scientific LLC. 


\section{Figure legends}

\section{Figure 1.}

(a) Model of a homodimeric PARN molecule (grey) bound to both terminal structures of an mRNA chain (black), i.e. to the 5' cap (red) and 3' poly(A)-tail. UTR, untranslated region; AUG, start codon; STOP, stop codon. Crystal structures of (b) truncated mouse PARN (residues 1-430, PDB code: 2A1R [35]) containing the nuclease and R3H domains complexed with $\mathrm{A}_{10}$; only the nuclease domains (green) with $\mathrm{A}_{3}$ (orange) are visible, $\mathrm{R} 3 \mathrm{H}$ is disordered; (c) truncated mouse PARN (residues 1-430, PDB code: 2A1S [35]) containing the nuclease (green) and R3H (red) domains; (d) truncated mouse PARN (residues 1-510, PDB code: 3D45 [38] containing the nuclease (green), R3H (disordered) and RRM (cyan) domain complexed with the mRNA 5' cap analogue, $\mathrm{m}^{7} \mathrm{GpppG}$ (CPK colors). The structures were visualized by PyMOL [58].

\section{Figure 2.}

AFM images of full length human PARN molecules in buffer recorded by tips with the radius of curvature of $20 \mathrm{~nm}$; (a) scan size $300 \mathrm{~nm} \times 300 \mathrm{~nm}$; (b) control; (c) zoomed fragment of (a); (d) large scan size $2.5 \mu \mathrm{m} \times 2.5 \mu \mathrm{m}$; (e) cross-sections as depicted in (c); (f) threedimensional representation of a single PARN molecule. Bars and the horizontal scale of the $3 \mathrm{D}$ view correspond to a scale of distances at the scanned area, and they do not reflect the real sizes of molecules. The latter were calculated (Table 1, Fig. 4a) considering magnification of the apparent image by the tip (see Experimental section). 


\section{Figure 3.}

AFM images of full length human PARN molecules in buffer recorded by tips with the radius of curvature of 2-3 nm; (a) scan size $385 \mathrm{~nm} \times 385 \mathrm{~nm}$; (b) zoomed fragment of (a); (c) scan size $680 \mathrm{~nm} \times 680 \mathrm{~nm}$; (d) control: chemically modified mica surface covered by buffer without PARN; (e) cross-sections as depicted in (b); (f) three-dimensional representation of a single PARN molecule. Bars and the horizontal scale of the 3D view correspond to a scale of distances at the scanned area, and they do not reflect the real sizes of molecules. The latter were calculated (Table 1, Fig. 4b) considering magnification of the apparent image by the tip (see Experimental section).

\section{Figure 4.}

Frequency histograms and Gaussian distributions for dimensions ( $a$, long axis; $b$, short axis; both corrected for tip broadening; and $h$, height) of PARN molecules measured with use of tips with the radius of curvature of (a) 2-3 nm and (b) $20 \mathrm{~nm}$.

\section{Figure 5.}

Distribution of apparent sizes of hydrated molecules of (a) full length human PARN and (b) the PARN fragment (443-560) encompassing the RRM and a C-terminal extension, expressed as hydrodynamic diameters, $D_{h}$, determined by DLS. (c) Gel filtration of PARN(443-560) by Superdex 200. Molecular size markers and peaks corresponding to monomer and dimer of PARN(443-560) are indicated.

\section{Figure 6.}

(a) Disorder probability prediction by DISOPRED [47] for full length human PARN. The black arrow points at a short, well ordered sequence fragment (amino acids 550-555) 
belonging to the C-terminal tail of the RRM. (inset) Disorder probability prediction for PARN(443-560) encompassing the RRM (amino acids 443-510) and its C-terminal tail (amino acids 511-560). The black arrow points at the well ordered HYYR motif (amino acids 551-554) within the C-terminal tail. (b) Arrangement of three PARN domains: the bipartite nuclease domain (residues 1-177 and 246-391), R3H (178-245), and RRM (437-510), aligned according to the residues numbers in (a). The black bar denotes the location of the Cterminally extended RRM fragment, i.e. PARN(443-560). (c) Secondary structure prediction by PSIPRED [48,49] for PARN residues 541-560, not present in the crystal structures of PARN fragments (Fig 1). The HYYR motif acquires $\beta$-strand conformation. Conf, confidence of prediction; Pred, predicted secondary structure; C, coil; H, helix; E, strand; AA, amino acid sequence. (d) Possible palindrome dimerisation of the sequence QNHYYRNN (549-556) motif. 


\section{Research Highlights}

AFM images show that a single PARN molecule form a compact ellipsoidal dimer.

Dimensions of the single protein molecule were determined as $10.9 \times 7.6 \times 4.6 \mathrm{~nm}$.

DLS was used to further characterise PARN and its fragment encompassing the RRM domain. 


\section{Table 1}

Dimensions ( $a$, long axis; $b$, short axis; $h$, height) and volume, $V$, of a full length human PARN molecule determined by contact-mode atomic force microscopy in buffer, and stoichiometric coefficient, $V / V_{\text {mono }}$, describing oligomeric state of detected species.

\begin{tabular}{|c|c|c|c|c|}
\hline Tip radius [nm] & & Dimension [nm] & $\mathrm{V}\left[\mathrm{nm}^{3}\right]$ & $\mathrm{V} / \mathbf{V}_{\text {mono }}{ }^{b}$ \\
\hline $2-3$ & $10.4 \pm 0.2$ & $\begin{array}{lll}7.7 & \pm 0.2 & 6.1 \pm 0.6\end{array}$ & $255 \pm 30$ & $2.6 \pm 0.3$ \\
\hline 20 & \pm 0.4 & $4.0 \pm 0.4$ & $190 \pm 19$ & $2.0 \pm 0.2$ \\
\hline weighted average & $10.87 \pm 0.19$ & $7.56 \pm 0.17$ & $196 \pm 15$ & $2.02 \pm 0.16$ \\
\hline
\end{tabular}

${ }^{a}$ Total errors including statistical errors (S.E.M of 0.08 and $0.10 \mathrm{~nm}$ for the sharp and broad tips, respectively) and different roughness of the modified mica surface detected by the tips. 100 molecules were measured.

${ }^{\mathrm{b}}$ Calculated molecular volume, $\mathrm{V}_{\text {mono }}$, corresponding to the PARN monomer equals $97\left[\mathrm{~nm}^{3}\right]$. 


\section{Table 2}

Average hydrodynamic diameters, $D_{h}$, molecular weights, $M W$, and $\%$ of sample polydispersity, $\% P d$, determined from dynamic light scattering experiments for full length human PARN and PARN(443-560); calculated molecular weights, $M W_{\text {mono }}$, corresponding to monomers of the polypeptides, and stoichiometric coefficients, $M W / M W_{\text {mono }}$, describing oligomeric state of species present in solution.

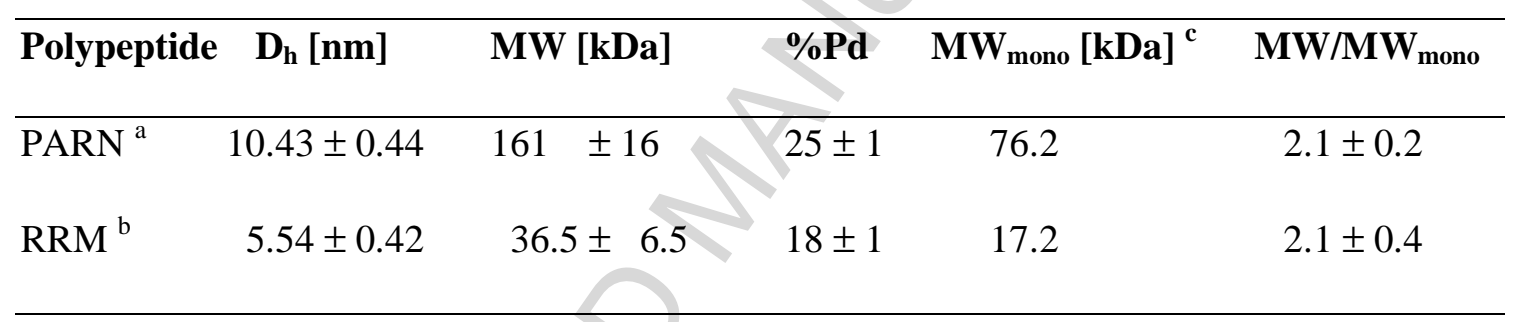

${ }^{\text {a }}$ His-tagged full length human PARN (residues 1-639)

${ }^{\mathrm{b}}$ His-tagged PARN fragment (residues 443-560) encompassing RRM (443-510)

${ }^{c}$ including His-tag 
Figure 1

(a)

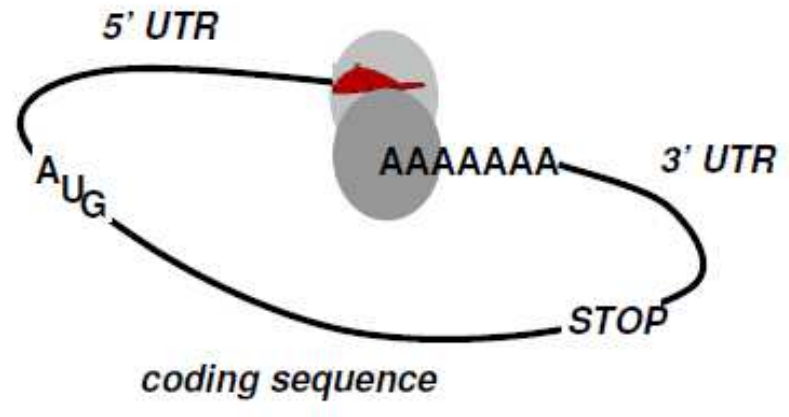

(b)

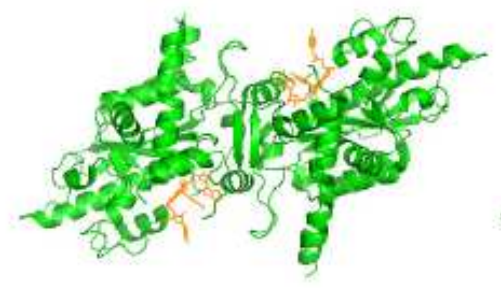

(c)

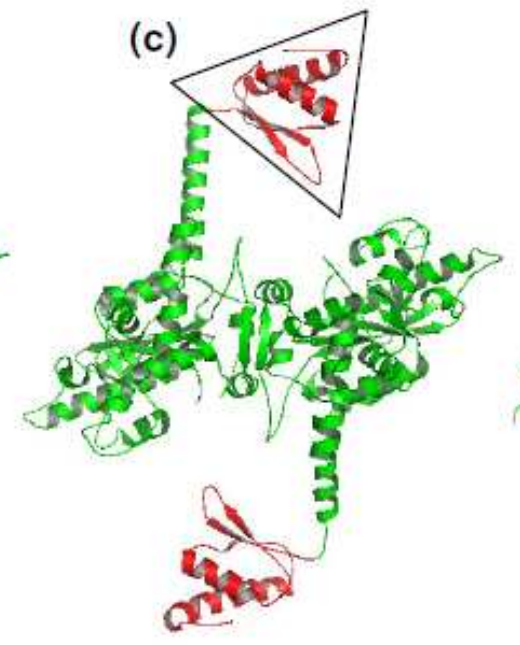

(d)

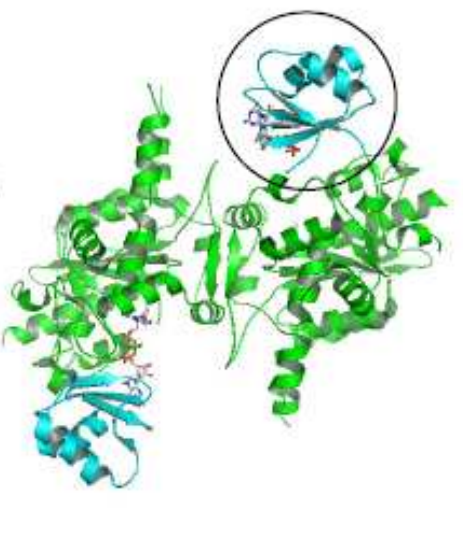


Figure 2

(a)

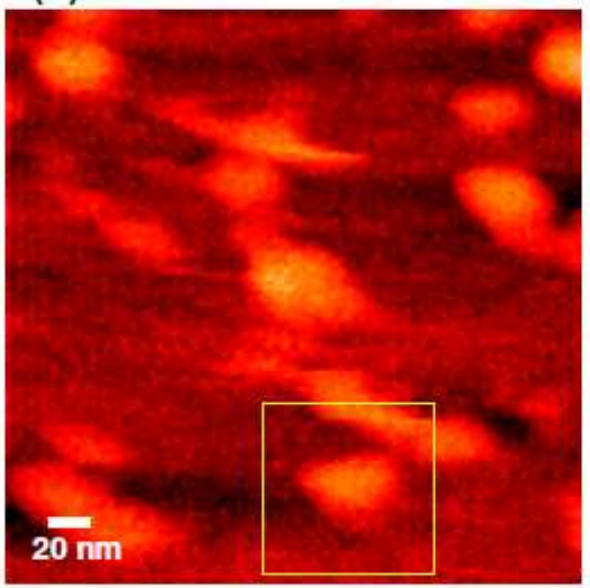

(c)

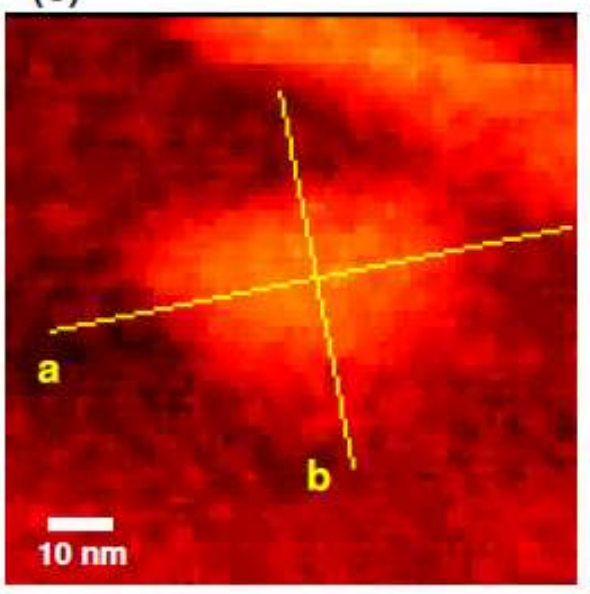

(e)
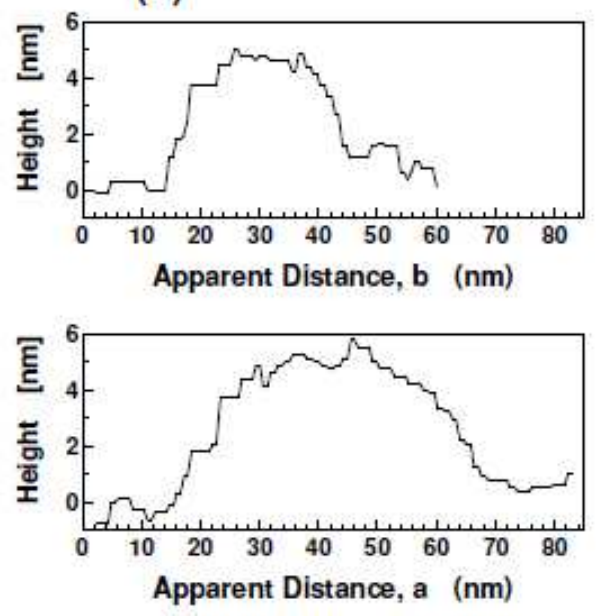

(b)

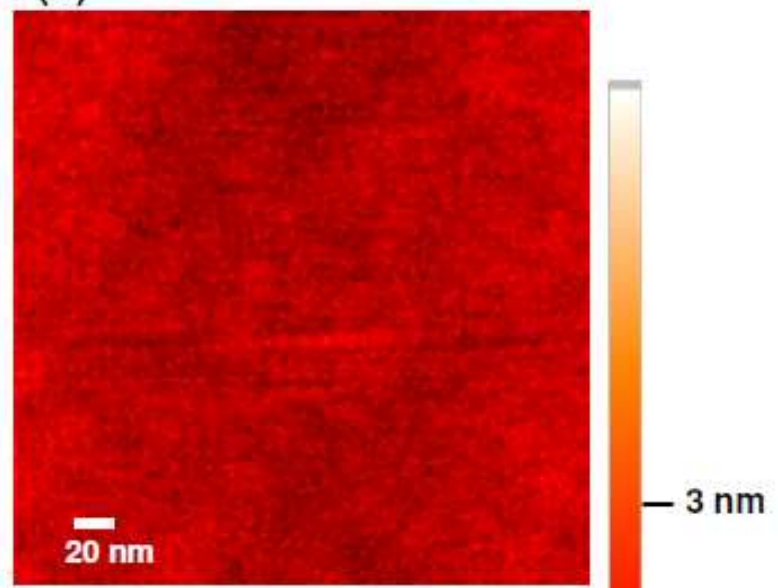

(d)

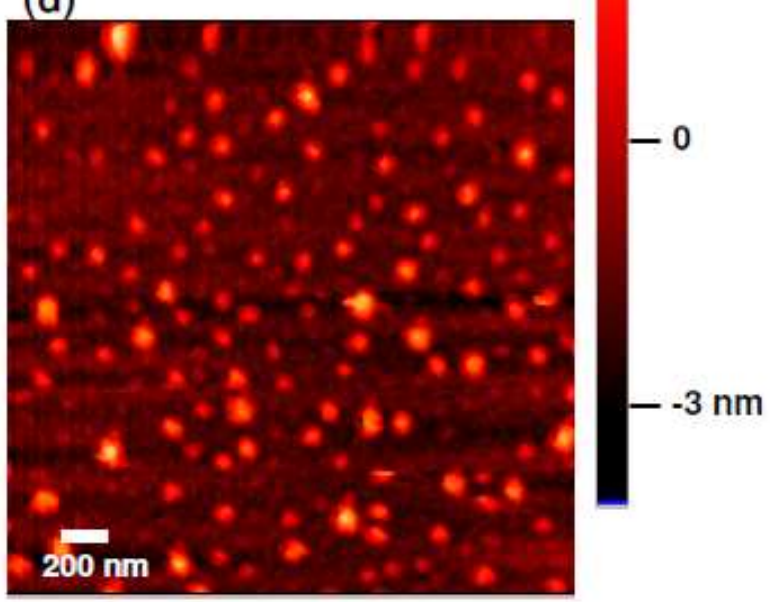

(f)

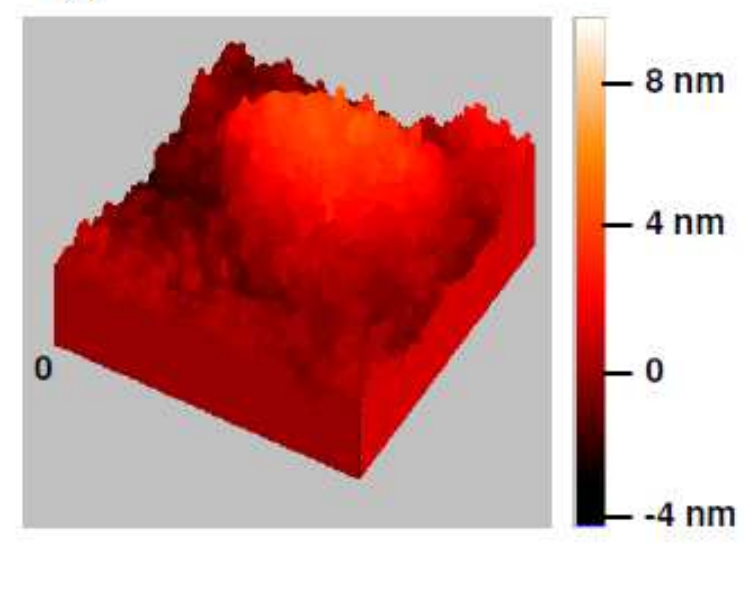


Figure 3

(a)

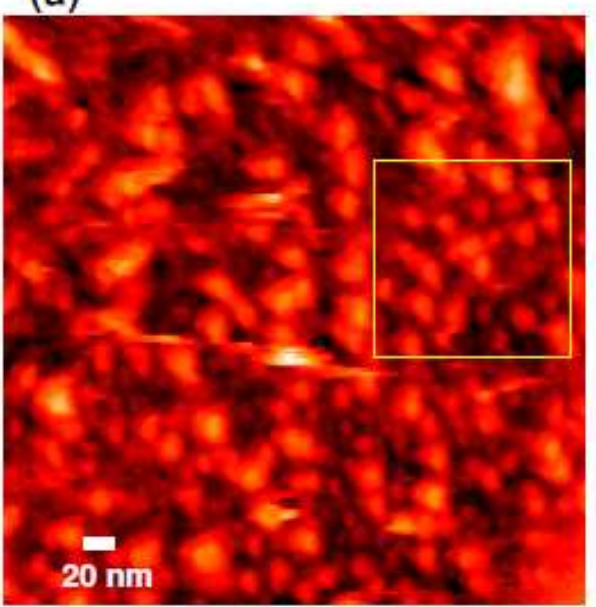

(c)

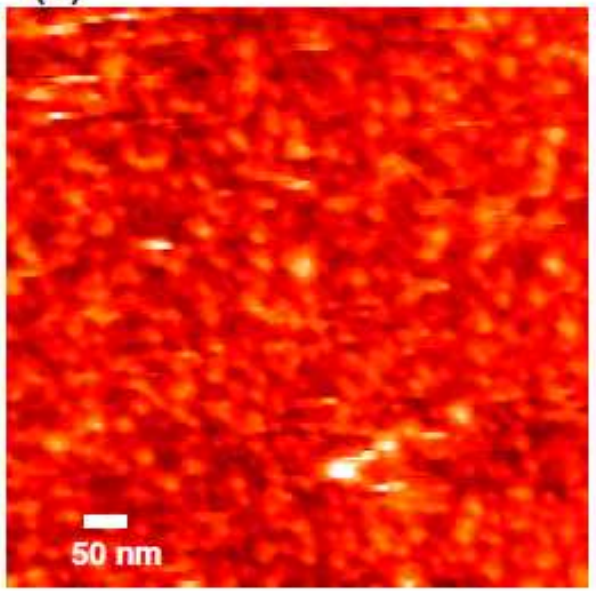

(e)
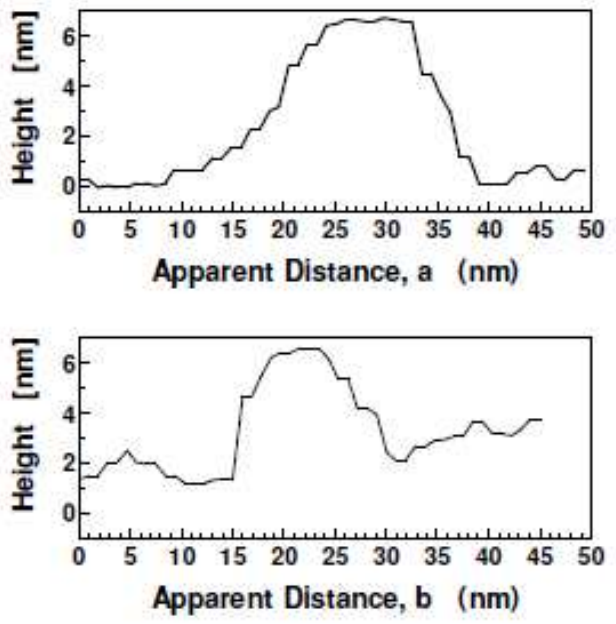

(b)

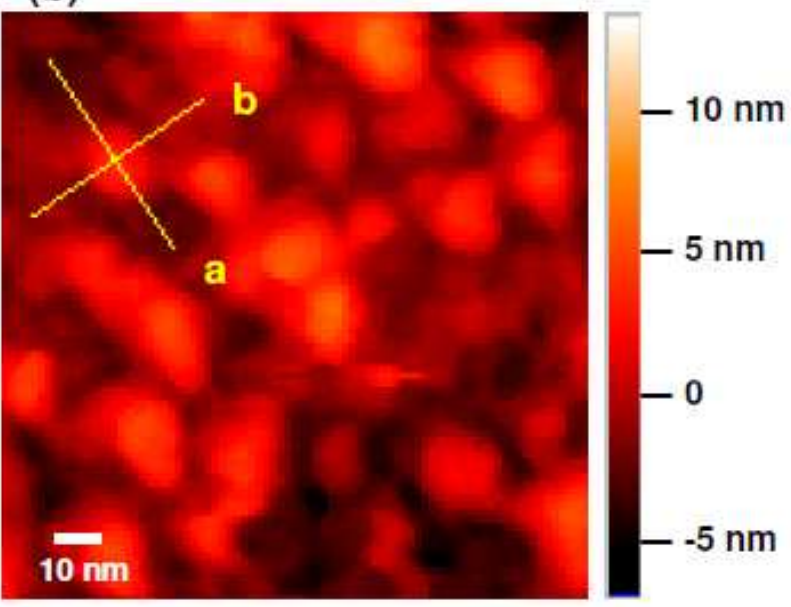

(d)

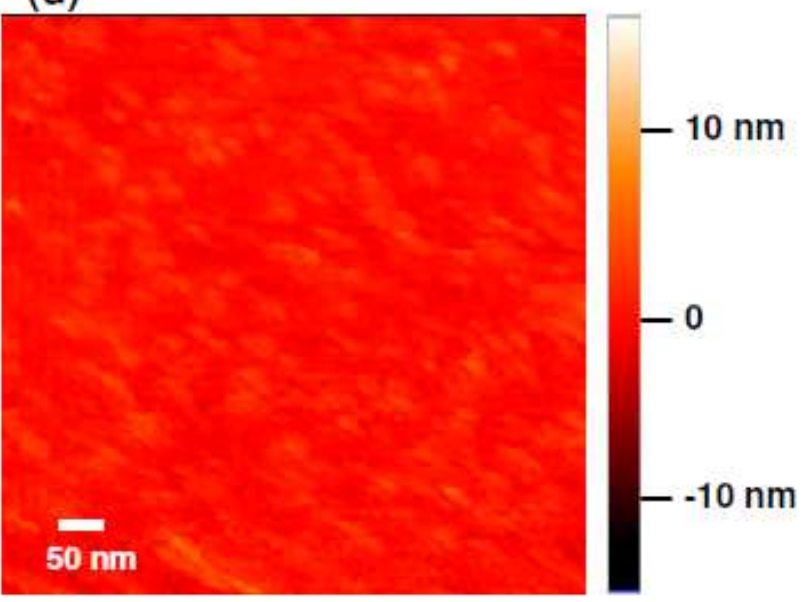

(f)

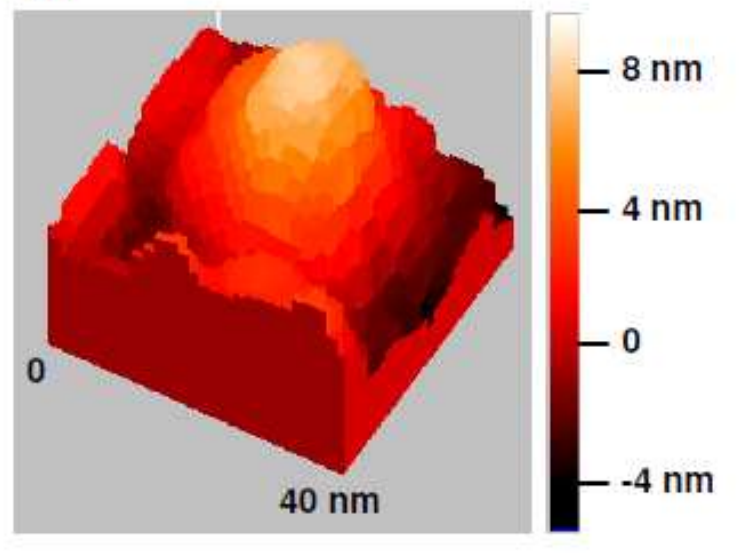


Figure 4

(a)

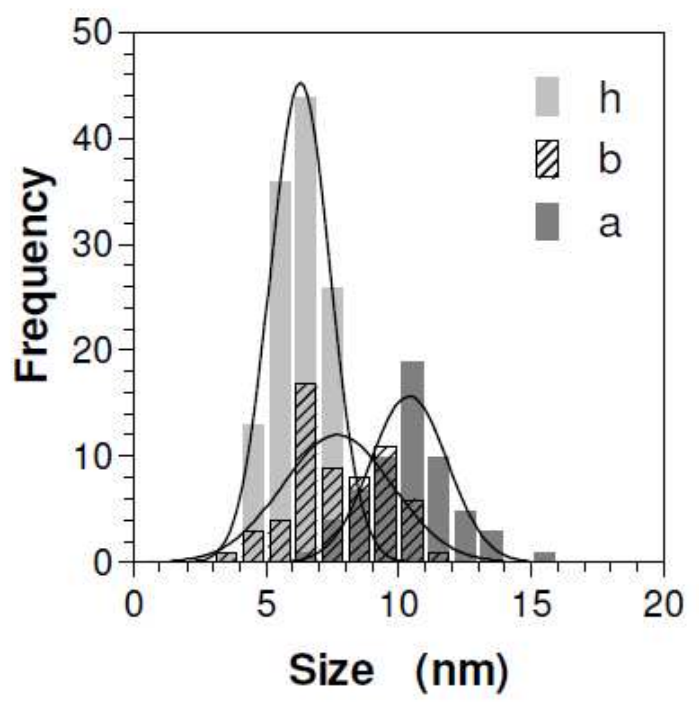

(b)

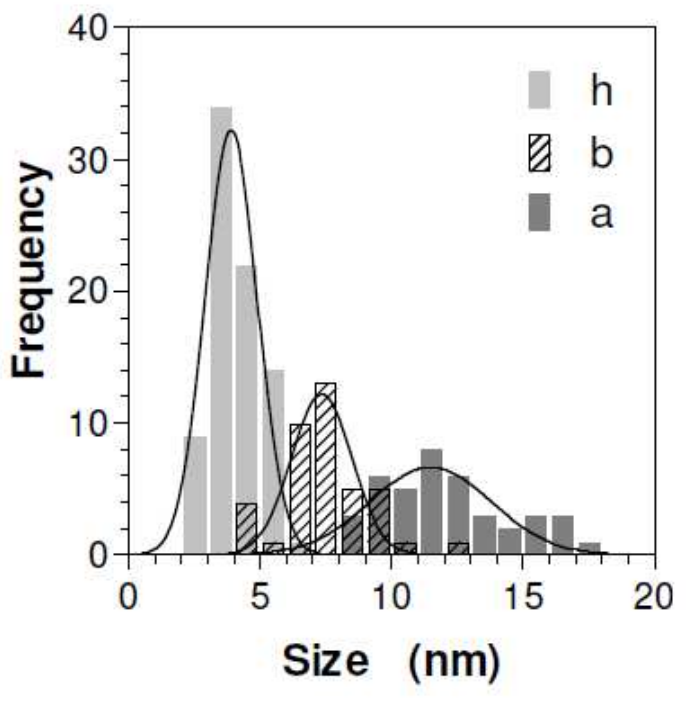


Figure 5

(a)

(b)
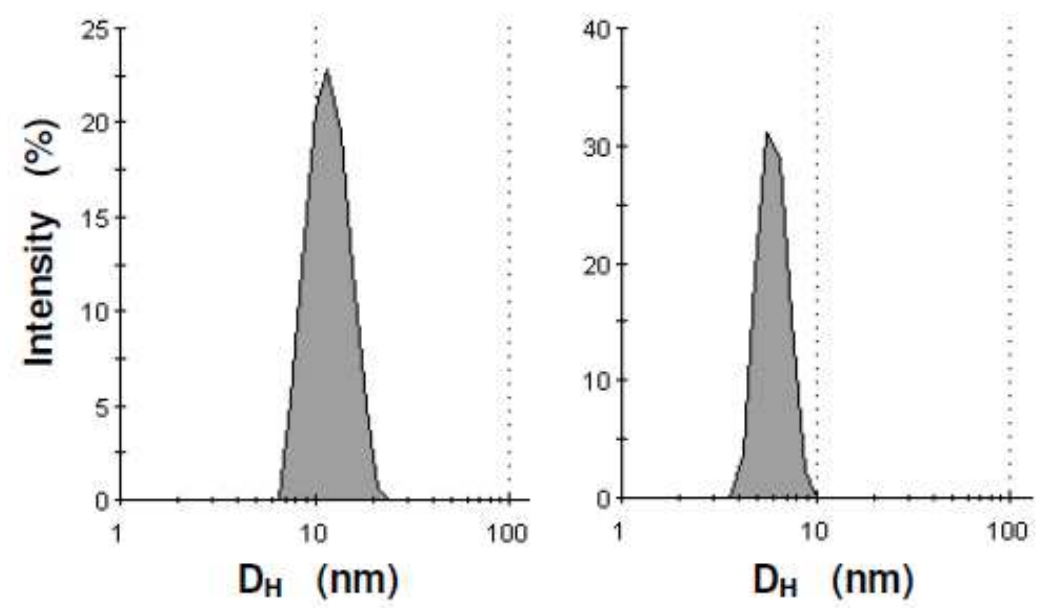

(c)

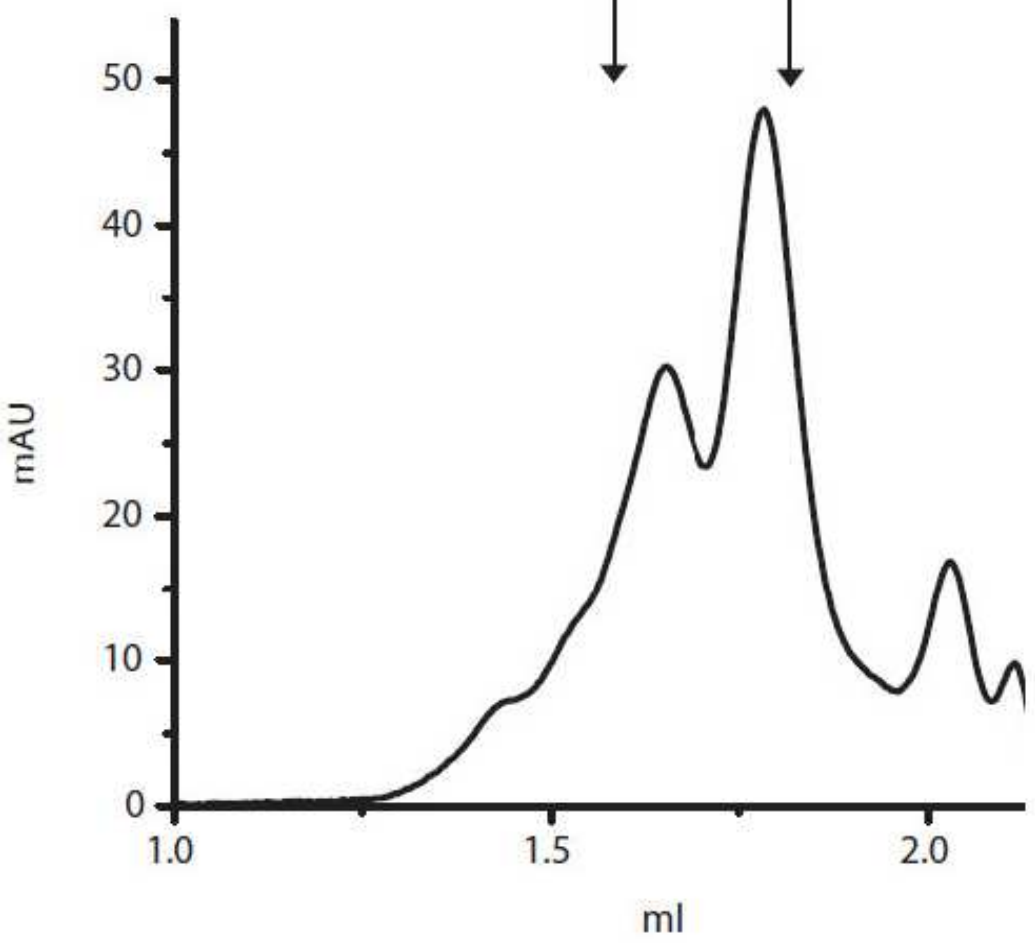


Figure 6

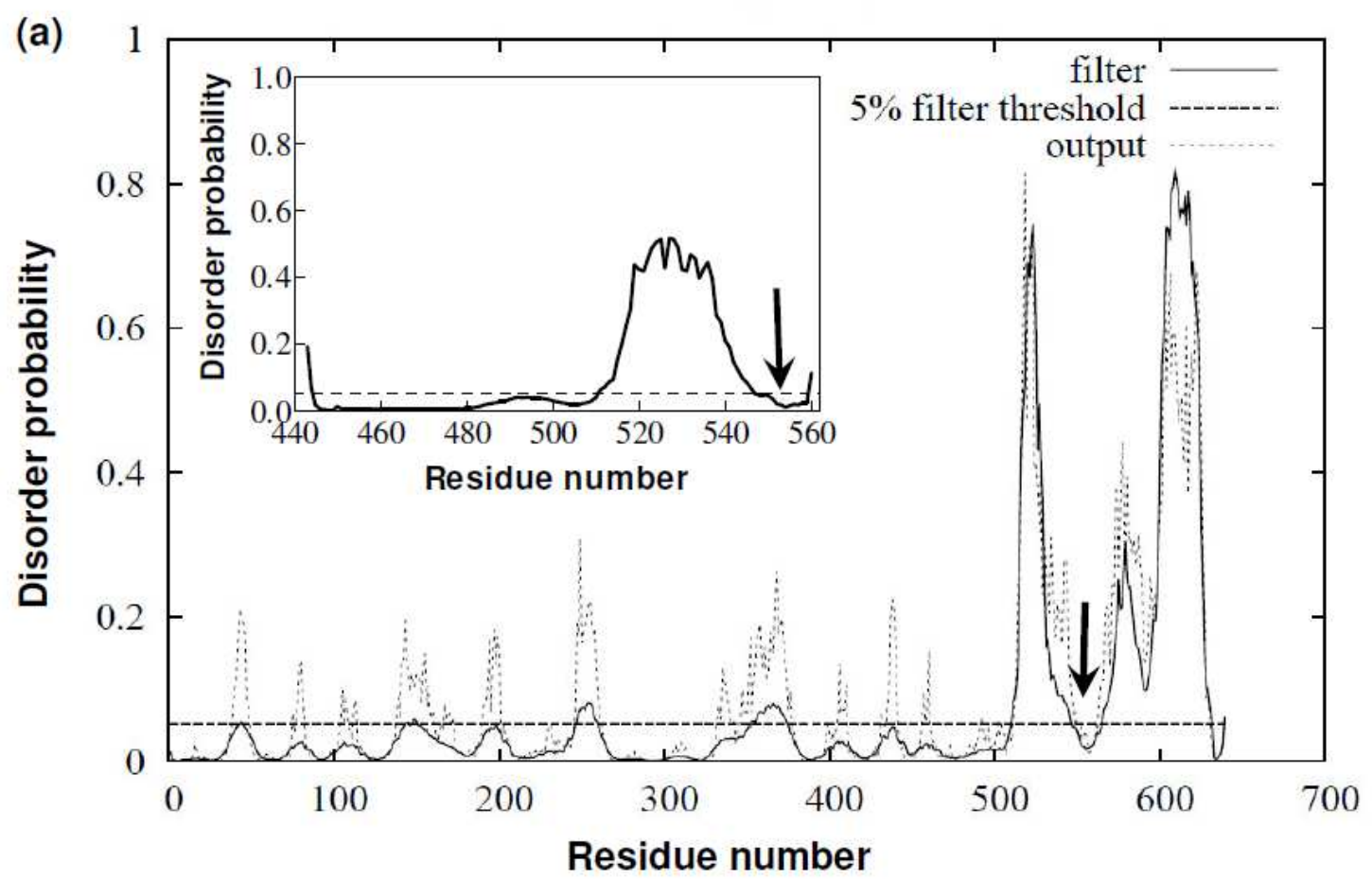

(b)

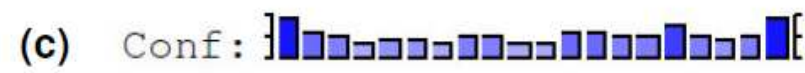

Pred:

Pred: CCCHHHHHHHEEEECCCCCC

AA: PQCIPYTLQNHYYRNNSETA (d)

LQNHYYRNNSF TA

ATESNNRYYHNQL 


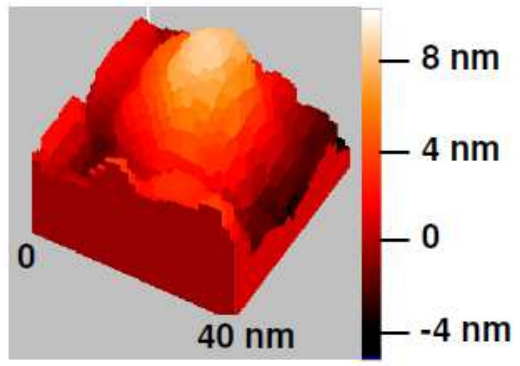

AFM image of poly(A)-specific 3'-exoribonuclease (PARN) dimer
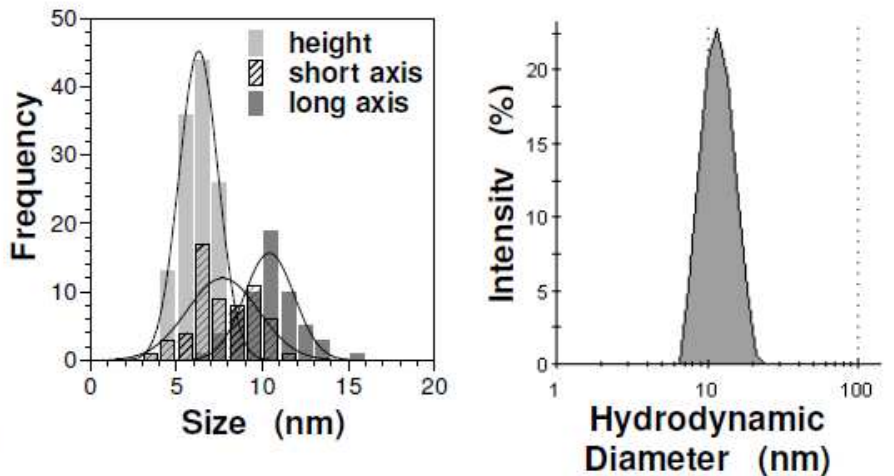

Graphical Abstract 